\title{
Psychosis and substance misuse comorbidity: ethical dilemmas
}

\author{
Rob Macpherson
}

\begin{abstract}
This case demonstrates some of the complex practical and logal difliculties in managing patients sutiering from comorbidity of substonce misuse and peychosis. A cliscusetion of the ethical lasues includes references to abeolutist and utiltiarian ethical models. Ethical dilemmas in such cases often impinge directly on clinical management, and the paper argues that the success or othenwise of treatment is portly dependent on owcreness of such foctors.
\end{abstract}

The problem of comorbidity of substance misuse and severe psychiatric illness is increasingly recognised (Smith \& Hucker, 1994). The Epidemiological Catchment Area Study (Regier et al, 1990) found life-time rates of substance misuse in patients with bipolar mood disorder of $56 \%$. Such cases often present complex clinical issues, and Smith \& Hucker (1994) have argued that education of professionals and a change in attitudes to treating patients with comorbidity is necessary. These patients' antisocial behaviour and failure to comply with treatment may be used as justification for refusing admission or premature discharge (Fariello \& Scheidt, 1989). This case report highlights some of the difficulties of treating a patient with comorbidity.

\section{Case report}

Mr S was admitted urgently following assessment by his GP. He described a week of increasing hyperactivity, and the clinical presentation was characteristic of mania.

Mr S's background suggested a number of important factors. He described an unhappy childhood, his relationship with parents deteriorating further through his teens when problems of delinquency and conduct disorder emerged. As his stbling succeeded steadily in academic and career terms, Mr S dropped further into a life of petty crime, truancy and drug use. Aged 18 years, he had his first of eight psychiatric admissions, several being through the courts or under an order of the Mental Health Act. Diagnosis was generally drug-induced psychosis, or mania with associated substance misuse. He had an extensive forensic history, with numerous convictions from the age of 12 for burglary and drug related crime.

$\mathrm{Mr} \mathrm{S}$ lived an isolated existence in a bedsit, his life revolving around drug misuse and efforts to obtain drugs. He admitted to taking LSD, drinking four to five litres of cider per day, and smoking one-eighth ounce of cannabis in the week prior to admission.

Mr S became more disturbed following admission, and by the second day he was aggressive, threatening, refusing treatment and demanding to be allowed home. He was detained under Section 2, and antipsychotic medication was initiated. Mr S was intensively nursed in a Special Care area of the ward where he became cooperative, settled and psychiatrically 'well' after a few days. Over the next month, Mr S's ward management proved problematic, as each time his condition improved and the level of nursing care was reduced, he absconded from the ward, being returned on three occasions by the police in an obviously intoxicated state, freely admitting to having used cannabis and cider to get "out of his head'. He said this was his only pleasure and he was frustrated by the restrictive ward regime, such that he 'had to escape'. In quite rational discussions he pointed out that he enjoyed cannabis and had no intention of changing a 15-year pattern of drug use after this admission.

Despite enforced treatment with a high dose depot antipsychotic, the unstable clinical situation continued throughout the period of Section 2 detention, and this was converted to a Section 3. At this time the multidisciplinary team decided that Mr S should be nursed separately for a period of at least one month, in the Special Care area, to stabilise the situation and prevent further access to drugs.

Mr S appealed against his Section, and the medical report to the hospital managers recommended continuing detention "to allow treatment under conditions which denied access to the illicit drugs and alcohol, which maintained the psychotic illness and complicated its management". It was explicitly stated that the effect of Mr S's basic personality on the current situation was unclear. particularly regarding his unpredictable temper. The social work report pointed to uncertainty in 
diagnosis. It suggested that the main focus of treatment was to get Mr S off his drugs, and that if his problems were due purely to substance misuse, compulsory treatment under the Mental Health Act (1983) was precluded. During interviews with the social worker, Mr S showed no sign of mental illness, and it was suggested that the restrictive hospital regime had a negative effect. which could explain his angry outbursts.

Following assessment the hospital managers decided not to order discharge and made no specific recommendation. Mr S was nursed in the Special Care area for a further two weeks, and then slowly reintroduced to the ward. Despite freely admitting use of large quantities of cannabis during home visits and weekend leave, he remained stable with no psychotic symptoms or aggression over the next few months leading to discharge. One year later he is followed up by a community psychiatric nurse, and is refusing depot medication. He continues to use cannabis and alcohol and his social circumstances are unchanged.

\section{Comments}

Mr S's presentation demonstrates some conceptual difficulties, as his substance misuse may be seen as the cause of a drug-induced psychosis, the trigger to an episode of bipolar disorder, a maintaining factor in an affective episode, or finally as a coincidental factor to this illness episode. The case was further complicated by evidence for a diagnosis of psychopathic personality disorder, raising the possibility of 'triple diagnosis'.

Diagnostic issues are of some consequence in terms of the legal position. It seems clear that the decision to detain $\mathrm{Mr} S$ and to restrict access to drugs was justified clinically in terms of treating his presenting mental disorder. Whether this also applied to treatment of briefer episodes of disturbance apparently asociated with drugs taken during his stay (when he was better, and the deprivation of drugs was part of a longer term treatment strategy), is less certain. Did this contravene Section 1 (5) of the Mental Health Act (1983), which states that a person cannot be dealt with under the act "by reason only of dependence on alcohol or drugs"?

This legal uncertainty unveils the first ethical dilemma. The clinical team considered that Mr S's substance misuse was partly motivated to avoid painful feelings of helplessness and inadequacy related to childhood deprivation and failure to achieve his potential in the eyes of his family. Hence the decision to prevent him from using drugs and alcohol can be seen as an assault on his defences of avoidance and denial. By denying his right to refuse the treatment did we cause a breakdown of ego defences, leading to emotional and behavioural disturbance?

A further dilemma concerns the possibility that Mr S's hostility and resistance to treatment were due to his personality rather than illness. Arguably, the somewhat punitive and penal regime adopted in this case may have reflected a feeling that Mr S was 'bad' rather than 'mad'. However, locking up drug-misusing personality disordered individuals to prevent their substance misuse seems dubious, not least because in neither diagnosis is compulsory treatment generally seen as being covered by the Mental Health Act (1983).

It is difficult to judge how far Mr S's confinement and exclusion from drug use contributed to his clinical improvement. In the later stages of his admission he had misused drugs during periods of leave from the ward, remaining psychiatrically well and at one year follow-up he was still out of hospital, despite free access to drugs in this period.

In the management of substance misuse, prescribing to minimise socially damaging effects is increasingly accepted as an effective long-term strategy. In this case, would permitting controlled substance use have been more successful? In theory this may improve treatment alliance, and avoid the confrontational, authoritarian stance which seemed to cause management difficulties. Fariello \& Scheidt (1989) argued that in treating substance misuse combined with serious psychiatric illness, a long-term approach which initially focuses on education and engagement is more likely to succeed than confrontation, and this means accepting that drug use will continue in early treatment. However, this is at odds with most psychiatric treatment which bans all inpatient substance use.

The corollary to this view was also evident in this case. Team members expressed concerns that $\mathrm{Mr}$ S's psychiatric label and in-patient status could be used to excuse petty crime and reduce his responsibility for antisocial behaviour. $\mathrm{Mr} \mathrm{S}$ had switched from recidivism in his early adult life, to become a revolving door psychiatric patient and this was seen by some as 'working the system'. It was of interest that MrS's final discharge coincided with the time his state benefits would have been reduced, due to his length of stay.

\section{Ethical issues}

There seem to be two levels of ethical consideration, regarding $\mathrm{Mr}$ S's restrictive management regime. First, Hare (1991) has described the 'absolutist' approach to resolving a moral question, in which 'inalienable rights' of the individual include an 'absolute duty to respect'. However, he points out that a major deficit of the model is its failure to determine what 'rights' exist, and which should, in the event of conflict, prevail: In the present case one could see Mr S as having a 'right' 
both to his freedom, and to recelve care in order to help him through his period of crisis. The scope of the medical 'duty of respect' has also not apparently been defined, and in absolutist terms it could be argued that the Mental Health Act is a contradiction to this concept. Can it ever be right to use 'harsh' measures, in so far as they are intended to be harsh?

Second, the utilitarian approach "assumes implicitly that doctors could perform their task without ethical difficulties by serving the best interests of their patients" (Hare, 1991). In the present case, much seemed to depend on a pragmatic judgement as to whether restrictive measures would be of benefit to the patient in the long term, and the needs of the wider society (to be protected from $\mathrm{Mr}$ S's aggression) clearly played an important part. This pre-eminence of the wider good over the individual is a necessary feature of the utilitarian approach, and an aspect of the present case which raised particular concerns was the danger to professionals caring for $\mathrm{Mr} \mathrm{S}$, against whom the full force of his resentment was expressed.

In approaching an ethical problem, it is usual to combine the above models. However, it could be argued that they fail to attend to the interactive nature of the clinical setting, and tend to see the patient as the location of the ethical dilemma, rather than as an individual with his/her set of responsibilities to society. Although $\mathrm{Mr} \mathrm{S}$ clearly did not want to give up cannabis, the question of what he did want from the professionals remains unanswered, and the fact that he has continued to accept follow-up one year after discharge implies recognition at some level of a need for help.

\section{Conclusion}

At present there is no clear view as to how best to manage this kind of clinical problem, and due to the legal and practical complexities, ethical dilemmas are inevitable. The approach in this case was to consider and address these openty through regular team meetings, and as far as possible to involve $\mathrm{Mr} \mathrm{S}$ in this process. Holmes et al (1994) have pointed out that medical ethics is often concerned with a dichotomous view of paternalism versus beneficence in medical care, and polarised views regarding management have been described in this case. Arguably, a dual diagnosis of substance misuse and psychosis inevitably introduces ambiguity, and successful management requires a willingness to acknowledge and work with the powerful feelings of passivity/aggression, seduction/rejection and helplessness/omnipotence, which are often engendered. In trying to help MrS, the clinical team faced many challenges. Whether these challenges were met effectively remains a question for the reader.

\section{References}

FARIEUO, D. \& SCHEIDT, S. (1989) Clinical care management of the dually diagnosed patient. Hospital and Community Psychiatry, 40, 1065-1067.

HARE, R. (1991) The philosophical basis of psychitatric ethics. In Psychiatric Ethics (eds S. Bloch \& P. Chodoff). Oxford: Oxford Untversity Press.

HOLMES, J., ADSHEAD, G. \& SMITH, J. (1994) An ethical dilemma in psychotherapy. Psychiatric Bulletin, 18 466-468.

Regier, D. A., FARMER, M. E., RAE, D. S., et al (1990) Comorbidity of mental disorders with alcohol and other drugs of abuse: results of the Epidemiologic Catchment Area Study. Journal of the American Medical Assoctation. 264. $2511-2518$.

SMITH, J. \& HUCKER, S. (1994) Schizophrenia and substance abuse. British Joumal of Psychiatry. 166, 13-21.

Rob Macpherson, Consultant Psychiatrist, Wotton Lawn, Horton Road, Gloucester GL1 3PX 